\title{
Identification and characterization of RAPD and SCAR markers linked to anthracnose resistance gene in sorghum [Sorghum bicolor (L.) Moench]
}

\author{
Monika Singh $\cdot$ K. Chaudhary $\cdot$ H.R. Singal • \\ C.W. Magill · K.S. Boora
}

(C) Springer Science + Business Media B.V. 2006

\section{Erratum to: Euphytica (2006) 149: 179-187 \\ DOI 10.1007/s10681-005-9065-4}

Due to an unfortunate error, the equation on page 182 of the above mentioned publication has been incorrectly displayed. The correct representation of the equation is published below and should be treated as definitive by the reader:

Map distance in Morgans ( $r$ ) was determined by using the following equation:

$r=R /(2-2 R)$

where $R$ represents the proportion of recombinant lines, $r$ represents the proportion of recombinants in a single meiosis.

The online version of the original article can be found at http://www.dx.doi.org/10.1007/s10681-005-9065-4

M. Singh $(\bowtie) \cdot$ K. Chaudhary $\cdot$ K.S. Boora

Department of Biotechnology and Molecular Biology, CCS Haryana Agricultural University, Hisar 125 004, Haryana, India

e-mail: monika_a_singh@ rediffmail.com

\section{H.R. Singal}

Department of Biochemistry, CCS Haryana Agricultural

University, Hisar 125 004, Haryana, India

C.W. Magill

Department of Plant Pathology and Microbiology,

Texas A \& M University, College Station, USA 